\title{
Topical Simvastatin Accelerates Wound Healing in Diabetes by Enhancing Angiogenesis and Lymphangiogenesis
}

Jun Asai, ${ }^{*}$ Hideya Takenaka, ${ }^{*}$ Satoshi Hirakawa, ${ }^{\dagger}$ Jun-ichi Sakabe, ${ }^{\dagger}$ Asami Hagura, ${ }^{*}$ Saburo Kishimoto, ${ }^{*}$ Kazuichi Maruyama, ${ }^{\neq}$ Kentaro Kajiya, ${ }^{\S}$ Shigeru Kinoshita, ${ }^{\ddagger}$ Yoshiki Tokura, ${ }^{\dagger}$ and Norito Katoh*

From the Departments of Dermatology* and Ophthalmology, ${ }^{*}$ Graduate School of Medical Science, Kyoto Prefectural University of Medicine, Kyoto; the Department of Dermatology, ${ }^{\dagger}$

Hamamatsu University School of Medicine, Hamamatsu; and the Shiseido Innovative Science Research Center, Yokohama, Japan

Impaired wound healing is a major complication of diabetes. Recent studies have reported reduced lymphangiogenesis and angiogenesis during diabetic wound healing, which are thought to be new therapeutic targets. Statins have effects beyond cholesterol reduction and can stimulate angiogenesis when used systemically. However, the effects of topically applied statins on wound healing have not been well investigated. The present study tested the hypothesis that topical application of simvastatin would promote lymphangiogenesis and angiogenesis during wound healing in genetically diabetic mice. A full-thickness skin wound was generated on the back of the diabetic mice and treated with simvastatin or vehicle topically. Simvastatin administration resulted in significant acceleration of wound recovery, which was notable for increases in both angiogenesis and lymphangiogenesis. Furthermore, simvastatin promoted infiltration of macrophages, which produced vascular endothelial growth factor $\mathrm{C}$ in granulation tissues. In vitro, simvastatin directly promoted capillary morphogenesis and exerted an antiapoptotic effect on lymphatic endothelial cells. These results suggest that the favorable effects of simvastatin on lymphangiogenesis are due to both a direct influence on lymphatics and indirect effects via macrophages homing to the wound. In conclusion, a simple strategy of topically applied simvastatin may have significant therapeutic potential for enhanced wound healing in patients with impaired microcirculation such as that in diabetes. (Am J Pathol 2012, 181:2217-2224; bttp:// dx.doi.org/10.1016/j.ajpath.2012.08.023)

Delayed wound healing is a major complication of diabetes and is caused by increased apoptosis, delayed cellular infiltration, reduced angiogenesis, and decreased formation and organization of collagen fibers. ${ }^{1-3}$ Impaired lymphangiogenesis has also recently been established as a major factor in diabetic refractory wound healing. ${ }^{4,5}$ The functions of lymphatic vessels in wounds are to drain the protein-rich lymph from the extracellular space, to maintain normal tissue pressure, and to mediate the immune response. ${ }^{6,7}$ Delayed wound healing, such as that seen in infections, appears to result from persistent edema and delayed removal of debris and inflammatory cells due to reduced lymphatic development. ${ }^{8}$

Statins are HMG-CoA (5-hydroxy-3-methylglutaryl-coenzyme A) reductase inhibitors that are primarily used to lower circulating cholesterol levels. In addition, statins have been found to protect against ischemic injury and stimulate angiogenesis in normocholesterolemic animals. ${ }^{9-11}$ This angiogenic effect is partially mediated by direct regulation of proliferation of endothelial cells and capillary morphogenesis via the Akt/PI3K pathway. ${ }^{11}$ Simvastatin has been found to enhance vascular endothelial growth factor (VEGF) production and improve wound healing in an experimental model of diabetes, ${ }^{12}$ and nitropravastatin stimulates reparative neovascularization and improves recovery from limb ischemia in type 1 diabetic mice. ${ }^{13}$ However, systemic administration at an extremely high dose was used to obtain angiogenic effects in

Supported by grants from the Ministry of Education, Culture, Sports, Science and Technology of Japan.

Accepted for publication August 15, 2012.

CME Disclosure: The authors of this article and the planning committee members and staff have no relevant financial relationships with commercial interest to disclose.

Supplemental material for this article can be found at http://ajp. amjapathol.org or at $h t t p: / / d x . d o i . o r g / 10.1016 /$. ajpath.2012.08.023.

Address reprint requests to Jun Asai, M.D., Ph.D., Department of Dermatology, Graduate School of Medical Science, Kyoto Prefectural University of Medicine, 465 Hirokoji, Kawaramachi, Kamigyo-Ku, Kyoto, 6028566, Japan. E-mail: jasai@koto.kpu-m.ac.jp. 
these studies, and this is inapplicable for clinical use as an angiogenic drug in patients with ischemic disorders. However, topical application of statins with avoidance of systemic adverse effects may be useful for cutaneous wound healing, in which angiogenesis plays a pivotal role. ${ }^{14}$ The lymphangiogenic effects of statins have not been widely investigated. In this study, we evaluated the effects of topical simvastatin on angiogenesis and lymphangiogenesis in a mouse model of impaired diabetic wound healing.

\section{Materials and Methods}

\section{Animals}

Genetically diabetic C57BLKS/J-m+/+Lepr ${ }^{\mathrm{db}}$ mice (db/db mice) were obtained from Clea Japan, Inc. (Tokyo, Japan). All procedures were performed in accordance with the guidelines of the Animal Care and Use Committees of Kyoto Prefectural University of Medicine.

\section{Creation of Wounds}

Mice were between 6 and 10 weeks old at the time of the study. Wounds were generated as described previously. ${ }^{15-17}$ In brief, after induction of deep anesthesia by i.p. injection of sodium pentobarbital (160 mg/kg), full-thickness, excisional skin wounds using 8-mm skin biopsy punches were made on the backs of mice, with one wound generated in each mouse. Each wound was covered with a semipermeable polyurethane dressing (OpSite; Smith and Nephew, Massillon, $\mathrm{OH}$ ) after topical application of simvastatin (Calbiochem, La Jolla, CA) in petroleum jelly (a mixture of $5 \mathrm{mg}$ of simvastatin and $995 \mathrm{mg}$ of jelly) or vehicle (petroleum jelly alone). Simvastatin in petroleum jelly (10 $\mathrm{mg}$ of the mixture containing $50 \mu \mathrm{g}$ of simvastatin) or vehicle were applied to the wound on days $0,4,7$, and 10 after creation of the wound.

\section{Monitoring of Wound Healing}

A total of $5 \mathrm{db} / \mathrm{db}$ mice were used at each time point. Wound healing was monitored by taking pictures with a digital camera (Nikon Coolpix 995; Nikon, Tokyo, Japan) on days $0,4,7$, and 14 after wound creation. Images were analyzed using ImageJ software version $1.46(\mathrm{NIH}$, Bethesda, MD) ${ }^{18}$ by tracing the wound margin with a high-resolution computer mouse and calculating the pixel area. Wound closure was calculated as follows: Percentage Closed $=[($ Area on Day $0-$ Open Area on Final Day)/Area on Day 0] $\times 100$, as described previously. ${ }^{15}$ The areas of the wounds were compared with Student's $t$-test with $P<0.05$ taken to indicate a significant difference.

\section{Histologic Score}

A histologic score was assigned in a masked manner as described previously. ${ }^{15}$ Briefly, each specimen received a score of 1 to 12 as follows: 1 to 3 , none to minimal cell accumulation and granulation tissue or epithelial migration; 4 to 6 , thin, immature granulation dominated by inflammatory cells but with few fibroblasts, capillaries, or col- lagen deposition and minimal epithelial migration; 7 to 9 , moderately thick granulation tissue, ranging from mainly inflammatory cells to more fibroblasts and collagen deposition; and 10 to 12, thick, vascular granulation tissue dominated by fibroblasts and extensive collagen deposition.

\section{Evaluation of Wound Angiogenesis and Lymphangiogenesis}

Sections were stained with rat anti-CD31 antibody (1:100) (BD Biosciences, San Jose, CA) or rabbit anti-LYVE-1 antibody (Upstate, Lake Placid, NY). Green fluorescence was generated by labeling with fluorescein isothiocyanate (FITC)-streptavidin (Vector Laboratories, Burlingame, CA) and biotinylated anti-rat or anti-rabbit antibody (both Vector Laboratories). Wound angiogenesis or lymphangiogenesis was analyzed by calculating the percentage of fluorescent area. ${ }^{16,19}$ Briefly, for each slide, an image of the granulation tissue at the wound margin was captured. ImageJ software was used to quantitate the fluorescence intensity. The mean percentage of fluorescent pixels of five images served as an index of the angiogenic or lymphangiogenic response.

\section{Evaluation of Macrophage Number, Phenotype, and VEGF-C Expression in Granulation Tissue}

Sections of wounds were stained with rat anti-F4/80 antibody (Invitrogen, Carlsbad, CA). Labeling with F4/80 was visualized with Cy3-conjugated anti-rat antibody (Vector Laboratories). Ten granulation tissue fields (two sections from each animal) were selected, and F4/80positive cells were counted. ${ }^{16}$ VEGF-C expression was evaluated using goat anti-VEGF-C antibody (Santa Cruz Biotechnology, Santa Cruz, CA) and FITC-conjugated anti-goat antibody (Vector Laboratories). To determine the phenotype of infiltrating macrophages, IL-13 and tumor necrosis factor (TNF) $\alpha$ expression was evaluated using goat anti-IL-13 antibody and goat anti-TNF- $\alpha$ antibody (Santa Cruz Biotechnology), respectively, and FITC-conjugated anti-goat antibody. F4/80-positive TNF$\alpha$-positive cells were defined as an M1 phenotype and F4/80-positive IL-13-positive cells as an M2 phenotype. In each slide, F4/80-positive cells, F4/80-positive TNF- $\alpha$-positive cells, and F4/80-positive IL-13-positive cells were counted, and percentages of TNF- $\alpha$-positive macrophages and IL-13-positive macrophages were evaluated. The mean percentages of TNF- $\alpha$-positive macrophages and IL-13-positive macrophages in five images were used as indexes of the M1 and M2 phenotypes, respectively.

\section{RNA Isolation, CDNA Synthesis, and Quantitative RT-PCR}

Tissue sections obtained in RNAlater (Ambion, Paisley, UK) were processed for RNA isolation, cDNA synthesis, and quantitative RT-PCR. ${ }^{16}$ VEGF-C, fibroblast growth factor 2, endothelial nitric oxide synthase, stromal cell-derived factor $1 \alpha$, and platelet-derived growth factor $\beta$ gene expression levels were normalized based on the level of an internal 
reference gene, 18S. The primers used in the study were obtained from QIAGEN (Dússeldorf, Germany).

\section{Cell Culture}

Primary human lymphatic endothelial cells (LECs) were collected as previously described. ${ }^{20}$ LECs were cultured at $37^{\circ} \mathrm{C}$ in $5 \% \mathrm{CO}_{2}$ in endothelial cell basal medium 2 (Lonza, Walkersville, MD) supplemented with $5 \%$ fetal bovine serum, human VEGF-A, human fibroblast growth factor 2, human epidermal growth factor, insulin-like growth factor 1, and ascorbic acid. Each experiment was conducted at least three times, with similar results. A representative experiment is shown.

\section{Western Blot Analysis}

Cells were lysed with RIPA buffer (Invitrogen) and sonicated. After sonication, cell lysates were centrifuged at $15,400 \times g$ for 20 minutes at $4^{\circ} \mathrm{C}$, and the supernatants were collected into fresh tubes. Then $4 \times$ SDS sample buffer with $0.1 \mathrm{~mol} / \mathrm{L}$ dithiothreitol was added to samples. Samples were boiled for 5 minutes at $95^{\circ} \mathrm{C}$, and $20-\mu \mathrm{g}$ extracts were separated by 10\% SDS-PAGE and electroblotted onto polyvinylidene difluoride membranes for 2 hours at $180 \mathrm{~mA}$. The membranes were incubated with rabbit anti-human Akt (pan) (C67E7) monoclonal antibody (Cell Signaling Technology, Danvers, MA), rabbit anti-human phospho-Akt (Ser473) (D9E) monoclonal antibody (Cell Signaling Technology), or mouse anti-GAPDH monoclonal antibody (Santa Cruz Biotechnology) and detected with horseradish peroxidase-conjugated goat anti-rabbit IgG (Bio-Rad, Hercules, CA) or horseradish peroxidaseconjugated goat anti-mouse IgG (Bio-Rad). Immunoblots were visualized using an ECL Plus Western Blotting Detection Reagents Kit (GE Healthcare, Little Chalfont, Buckinghamshire, UK) according to the manufacturer protocol.

\section{Chord Formation Assay}

LECs were used in a chord formation assay. ${ }^{21}$ An aliquot $(100 \mu \mathrm{L})$ of growth factor-depleted Matrigel (Becton Dick- inson, Bedford, MA) was added to a 24-well dish and allowed to gel for 30 minutes at $37^{\circ} \mathrm{C}$. LECs were seeded at $5 \times 10^{4} \mathrm{cells} / \mathrm{mL}$ in $500 \mu \mathrm{L}$ of endothelial cell basal medium 2 containing 3\% fetal bovine serum. Cells were cultured in the absence or presence of various doses of simvastatin (Calbiochem, Darmstadt, Germany) with or without pretreatment with a PI3 kinase inhibitor, LY294002 (50 $\mu \mathrm{mol} / \mathrm{L})$ (ENZO Life Sciences, Plymouth Meeting, PA), the mTOR/ raptor inhibitor rapamycin (100 nmol/L) (Merck Millipore, Darmstadt, Germany), or the PI3K/mTOR inhibitor wortmanninrapamycin (100 nmol/L) (Cayman Chemical, Ann Arbor, MI) for 30 minutes. Chord formation was monitored for 24 hours. Digital pictures were taken using a spot image analysis system, and the total length of the chord-like structures at 12 hours was outlined and measured using ImageJ software.

\section{Proliferation Assay}

The proliferative activity of cells treated with simvastatin was examined using a CellTiter 96 nonradioactive cell proliferation assay (Promega, Madison, WI). Briefly, subconfluent cells (5000 cells per well) were reseeded on 96-well, flatbottomed plates with $100 \mu \mathrm{L}$ of growth media. The cells were treated with simvastatin and incubated for 48 hours at $37^{\circ} \mathrm{C}$. Absorbance at $570 \mathrm{~nm}$ was recorded using a 96-well enzyme-linked immunosorbent assay (ELISA) plate reader.

\section{Apoptosis Assay}

An apoptosis assay was performed using a DeadEnd Fluorometric TUNEL System (Promega). Briefly, LECs were plated on chamber slides and placed in medium. Cells were stimulated by simvastatin and incubated for 24 hours with medium containing $400 \mu \mathrm{mol} / \mathrm{L} \mathrm{H}_{2} \mathrm{O}_{2}$. To quantify apoptosis, 400 nuclei from random microscopic fields were analyzed by an observer masked to the treatment groups. The number of apoptotic cells was expressed as a percentage of the total cell count.
A

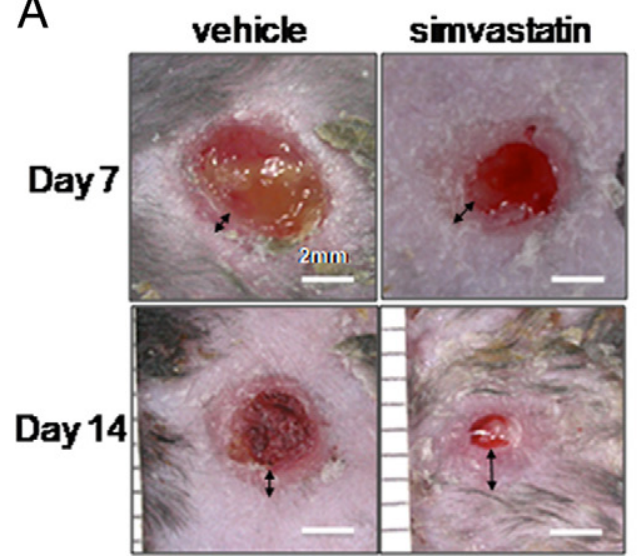

B

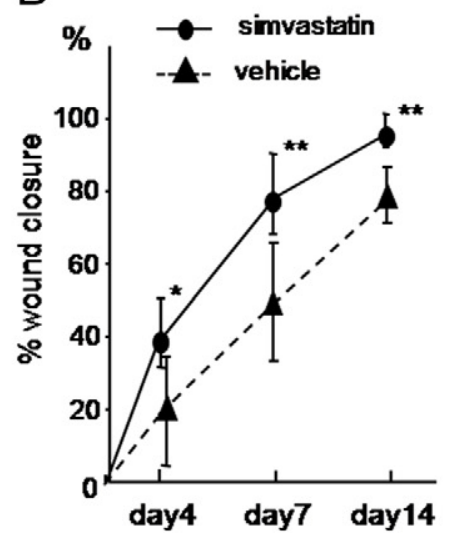

C

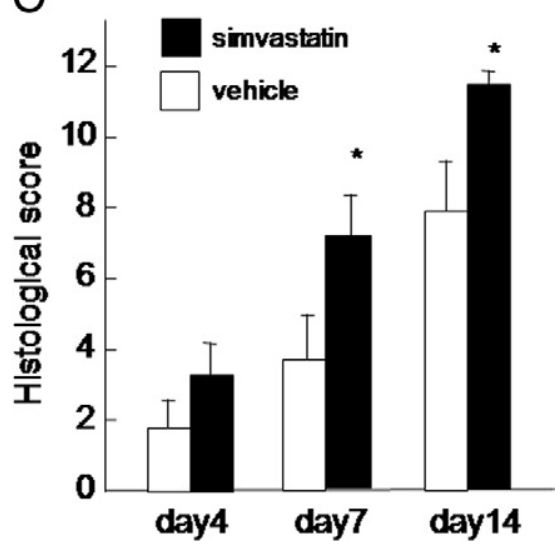

Figure 1. Effects of topical simvastatin on wound closure and histologic score in $\mathrm{db} / \mathrm{db}$ mice. A: Representative macroscopic views of wounds after different treatments and periods. Scale bar $=2 \mathrm{~mm}$. Arrows indicate the epithelialized range. B: Wound closure was measured on days 4,7 , and 14 . ${ }^{*} P<0.05$, ${ }^{* *} P<0.001$ versus vehicle ( $n=5$ in each group). C: Histologic scores for days 4,7 , and 14, quantified as described in Materials and Methods. Higher histologic scores indicate a greater extent of wound healing. ${ }^{*} P<0.05$ versus vehicle $(n=5$ in each group). 


\section{A \\ vehicle \\ simvastatin}
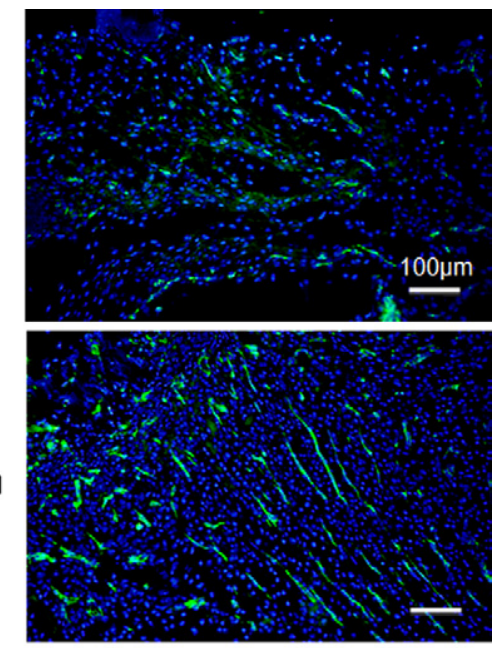

B

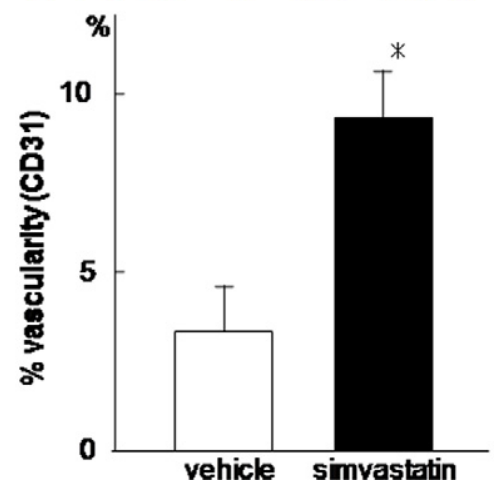

Figure 2. Effects of simvastatin on vascularity in granulation tissues at the wound margin in $\mathrm{db} / \mathrm{db}$ mice. A: Neovascularization at the wound margin in simvastatin- or vehicle-treated diabetic mice after 14 days. Original magnification, $\times 100$. Scale bar $=100 \mu \mathrm{m}$. Green and blue fluorescence corresponds to CD31-positive newly formed blood vessels and DAPI-labeled nuclei, respectively. B: Percentage of vascularity, quantified as described in Materials and Methods. ${ }^{*} P<0.001$ versus vehicle ( $n=5$ in each group)

\section{Statistical Analysis}

All results are presented as mean \pm SEM. Statistical comparisons between two groups were performed by Student's $t$-test. Multiple groups were analyzed by oneway analysis of variance followed by appropriate post hoc tests to determine statistical significance. $P<0.05$ was considered significant. All in vitro experiments were performed at least in triplicate.

\section{Results}

\section{Simvastatin Accelerates Wound Healing in Diabetic Mice}

Wound areas on days 7 and 14 in simvastatin- or vehicletreated diabetic mice are shown in Figure 1A. On day 14, simvastatin-treated wounds had more than 90\% epithelialization, whereas $<80 \%$ of the wound was epithelialized in the vehicle-treated group (Figure 1B). Simvastatin treatment resulted in significantly smaller wound areas after 4,7 , and 14 days. The difference in percentage of wound closure reached a maximum on day 7 (simvastatin versus control: $79.26 \% \pm 11.09 \%$ versus $52.45 \% \pm$
16.81\%; $P<0.001)$. The histologic score reflects the degree of maturation of granulation tissue, including inflammation, collagen deposition, and reepithelialization, in addition to neovascularization; therefore, higher histologic scores reflect a greater extent of wound healing. The histologic scores for wounds treated with simvastatin were significantly higher than those in the vehicle-treated group (day 4: $3.6 \pm 0.70$ versus $1.9 \pm 0.73$; day $7: 7.3 \pm$ 0.94 versus $3.7 \pm 0.94, P<0.01$; day $14: 11.6 \pm 0.51$ versus $8.0 \pm 1.15, P<0.01$ )(Figure $1 \mathrm{C}$ ).

\section{Simvastatin Promotes Both Angiogenesis and Lymphangiogenesis}

Wound angiogenesis was analyzed by immunostaining of an endothelial cell-specific marker, CD31, in 10- $\mu \mathrm{m}$ frozen sections to visualize neovascularization. Figure 2A shows neovascularization at the margin in simvastatin- or vehicle-treated wounds in diabetic mice on day 14. A few small vessels were seen at the wound margin in the vehicle-treated group, whereas large numbers of vessels were growing toward the center of the wound in the
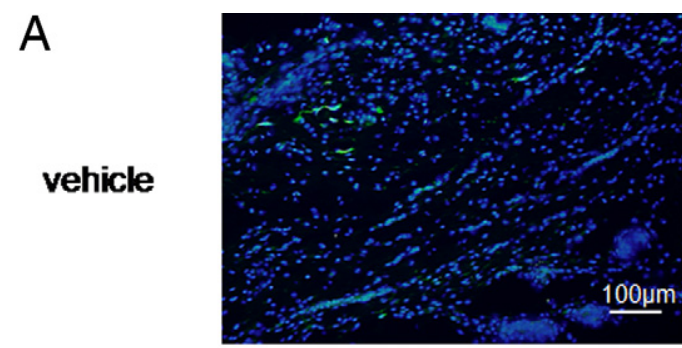

simvastatin

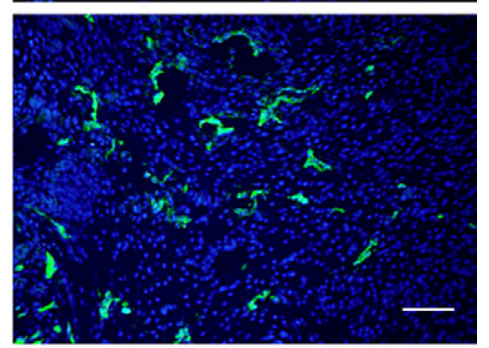

B

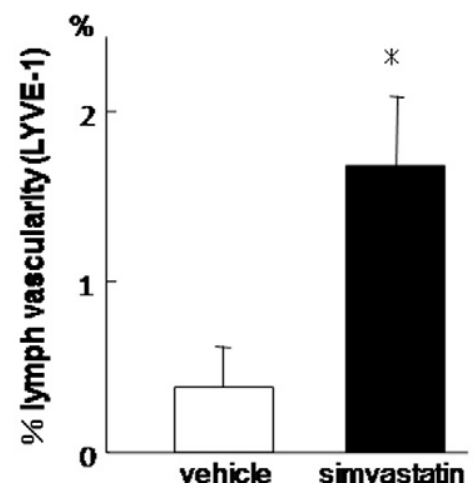

Figure 3. Effects of simvastatin on lymphangiogenesis in granulation tissues at the wound margin in $\mathrm{db} / \mathrm{db}$ mice. A: Lymphangiogenesis at the wound margin in simvastatin- or vehicle-treated diabetic mice after 14 days. Original magnification, $\times 100$. Scale bar $=100 \mu \mathrm{m}$. Green and blue fluorescence corresponds to LYVE-1positive newly formed lymphatic vessels and DAPI-labeled nuclei, respectively. B: Percentage of lymphatic vascularity, quantified as described in Materials and Methods. ${ }^{*} P<0.001$ versus vehicle ( $n=5$ in each group). 
A
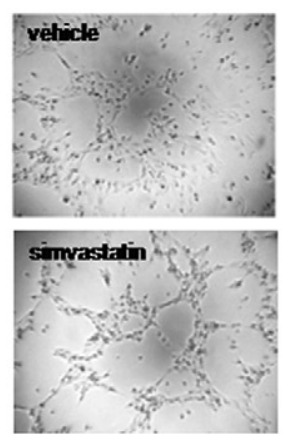

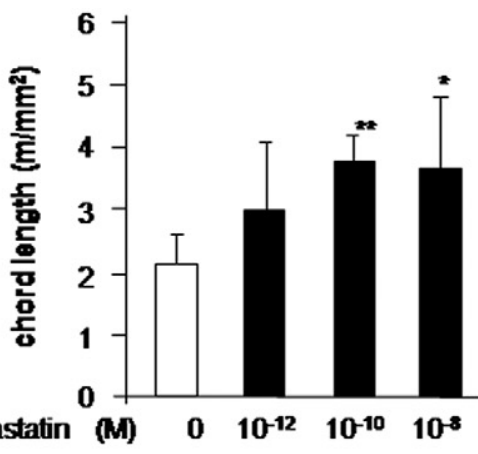

C
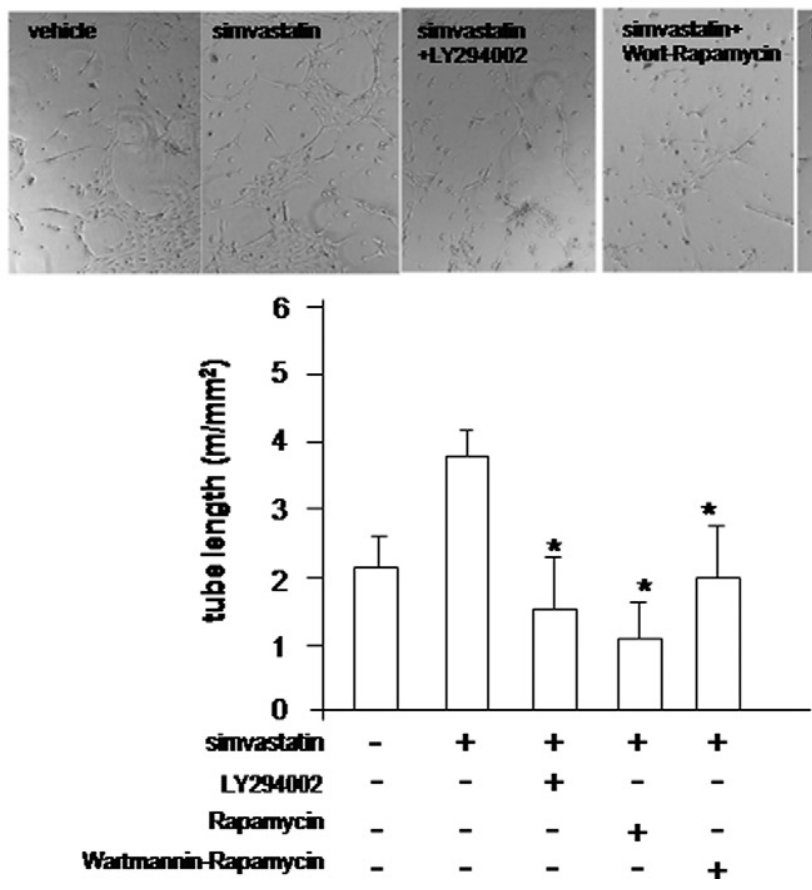

\section{B Phospho-Akt}

Total Akt

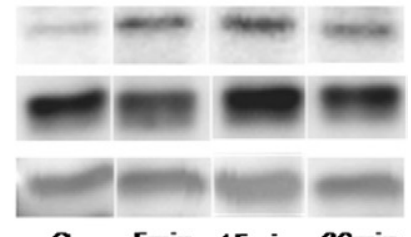

C 5 min $15 \min 30 \mathrm{~min}$

Figure 4. Effects of simvastatin on chord formation by LECs. A: Capillary morphogenesis of LECs in the presence of vehicle or simvastatin was investigated by chord formation assay. Phase contrast micrographs of LECs are shown in the presence or absence of simvastatin (left panel). Original magnification, $\times 10$. The bar chart (right panel) shows the chord length, quantified as described in Materials and Methods. ${ }^{*} P<0.05,{ }^{* *} P<0.001$ versus vehicle ( $n=6$ from three independent experiments). B: Western blot analysis of LECs treated with simvastatin $\left(10^{-10} \mathrm{~mol} / \mathrm{L}\right)$ for 5,15 , and 30 minutes. Immunoblots with total cell lysates were probed with antiAkt, anti-phospho-Akt (Ser473), and anti-GAPDH antibodies. C: Phase contrast micrographs of LECs cultured in the absence or presence of simvastatin $\left(10^{-10} \mathrm{~mol} / \mathrm{L}\right)$ with or without pretreatment with the PI3 kinase inhibitor LY294002 $(50 \mu \mathrm{mol} / \mathrm{L})$, the $\mathrm{mTOR} /$ raptor inhibitor rapamycin $(100 \mathrm{nmol} / \mathrm{L})$, or the $\mathrm{PI} 3 \mathrm{~K} / \mathrm{mTOR}$ inhibitor wortmannin-rapamycin $(100 \mathrm{nmol} / \mathrm{L})$ for 30 minutes (top panels). Original magnification, $\times 10$. The bar chart (bottom panel) shows the chord length. ${ }^{*} P<0.05$ versus simvastatin ( $n=6$ from three independent experiments).

simvastatin group. Simvastatin significantly enhanced wound vascularity based on image analysis of the percentage of the fluorescent area $(9.29 \% \pm 1.29 \%$ versus $3.25 \% \pm 1.33 \% ; P<0.001$ )(Figure $2 \mathrm{~B}$ ). Wound lymphangiogenesis was analyzed by immunostaining of a LECspecific marker, LYVE-1, in 10- $\mu \mathrm{m}$ frozen sections. Figure 3A shows new lymphatic vessels at the margin of simvastatin- or vehicle-treated wounds in diabetic mice on day 14. Wound lymphatic vascularity was significantly enhanced by simvastatin (percentage of fluorescent area: $1.72 \% \pm 0.460 \%$ versus $0.395 \% \pm 0.260 \% ; P<0.001)$ (Figure 3B). New vessels and lymphatics in granulation tissue in both groups were not covered with $\alpha$-smooth muscle actin-positive mural cells (see Supplemental Figure S1 at http://ajp.amjpathol.org).

\section{Simvastatin Induces Capillary Morphogenesis of LECs and Has an Antiapoptotic Effect but Does Not Induce Proliferation}

To characterize the effects of simvastatin on lymphangiogenesis, we performed a chord formation assay in primary human LECs in vitro. Treatment with simvastatin promoted LEC chord formation in a dose-dependent manner (Figure 4A). This effect was significantly blocked by the PI3 kinase inhibitor LY294002, the mTOR inhibitor rapamycin, and the PI3/mTOR inhibitor wortmannin-rapamycin $(P<0.05)$ (Figure $4 \mathrm{C})$. The proliferative and antiapoptotic effects of simvastatin on LECs were also examined because these are major effects of simvastatin in vascular endothelial cells. Simvastatin did not promote LEC proliferation, even at higher concentrations, and seemed to be slightly cytotoxic at $10^{-6} \mathrm{~mol} / \mathrm{L}$ and $10^{-5}$ $\mathrm{mol} / \mathrm{L}$ (Figure 5A). However, simvastatin treatment resulted in significant inhibition of $\mathrm{H}_{2} \mathrm{O}_{2}$-induced apoptosis compared with controls (Figure 5B).

\section{Simvastatin Promotes Macrophage Infiltration and VEGF-C Production in Wounds}

The number of macrophages in granulation tissues was evaluated in wounds on day 7 . This timing was chosen because reepithelialization was almost complete on day 14 in simvastatin-treated wounds, and inflammatory cells had already diminished. The number of macrophages in simvastatin-treated wounds on day 7 was significantly 
A

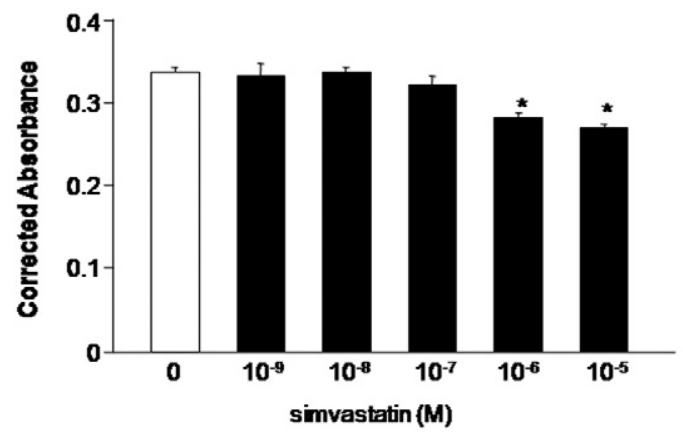

B

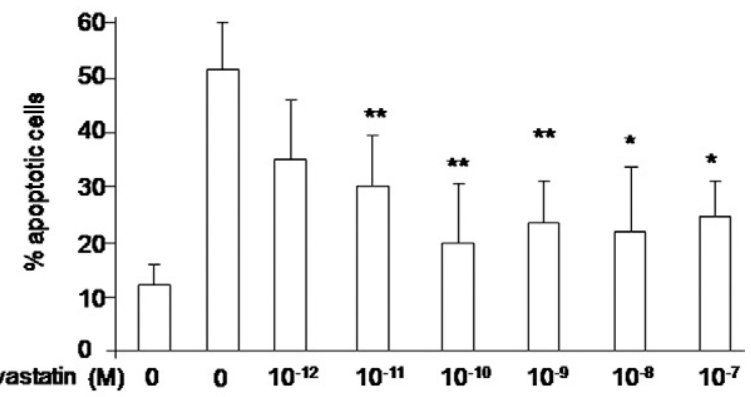

$\mathrm{H}_{2} \mathrm{O}_{2}(400 \mu \mathrm{M})-++\quad+\quad+\quad+\quad+\quad+$

Figure 5. Effects of simvastatin on proliferation and apoptosis of LECs. A: Cell proliferation of LECs was investigated by MTS assay. Subconfluent cells (5000 cells per well) were reseeded on 96-well, flat-bottomed plates with $100 \mu \mathrm{L}$ of growth media. The cells were treated with simvastatin and incubated for 48 hours at $37^{\circ} \mathrm{C}$. Absorbance at $570 \mathrm{~nm}$ was recorded using a 96-well ELSIA plate reader. Quantification was performed as described in Materials and Methods. ${ }^{*} P<0.05$ versus vehicle $(n=8$ from three independent experiments). B: Cell apoptosis in LECs was investigated by TUNEL assay. LECs were plated on chamber slides and placed in medium. Cells were stimulated by simvastatin and incubated for 24 hours with medium containing $400 \mu \mathrm{mol} / \mathrm{L} \mathrm{H}_{2} \mathrm{O}_{2}$. Quantification of apoptotic cells was performed as described in Materials and Methods. ${ }^{*} P<0.05$, ${ }^{* * *} P<0.01$ versus $\mathrm{H}_{2} \mathrm{O}_{2}$ treatment ( $n=3$ from three independent experiments).

greater than that in controls (Figure 6, A and B). Most of the macrophages in the simvastatin-treated group expressed the M2 marker, IL-13, rather than the M1 marker, TNF- $\alpha$, whereas most macrophages in the vehicletreated group expressed TNF- $\alpha$ rather than IL-13 (Figure $6, \mathrm{C}-\mathrm{F})$. The macrophages in the simvastatin-treated group produced VEGF-C (Figure 7A), and VEGF-C expression was significantly up-regulated in simvastatintreated wounds compared with controls (Figure 7B). Other proangiogenic mediators in wound granulation tissue were evaluated by real-time PCR. Platelet-derived growth factor $\beta$, endothelial nitric oxide synthase, and fibroblast growth factor 2 were significantly up-regulated by simvastatin stimulation (see Supplemental Figure S2 at http://ajp.amjpathol.org).

\section{Discussion}

In this study, we found that topical application of simvastatin accelerated diabetic wound healing via promotion of angiogenesis and lymphangiogenesis. Many studies have reported that statins, including simvastatin, have strong angiogenic effects on vascular endothelial cells or placental stem cells and that these effects are mainly mediated by the PI3-kinase/Akt pathway, ${ }^{11,22,23}$ although we note that other findings have also been reported ${ }^{24}$ Consistent with these reports, abundant neovascularization and proangiogenic growth factors were observed in wounds treated with topical simvastatin in our in vivo study. Statins were originally introduced as systemic antihyperlipidemic drugs; however, a recent study has shown the value of topical simvastatin. ${ }^{14}$ An advantage of topical application is that a suitable concentration of simvastatin can be applied without a risk of serious systemic adverse effects, such as rhabdomyolysis. Our results suggest that topical application of simvastatin could be a
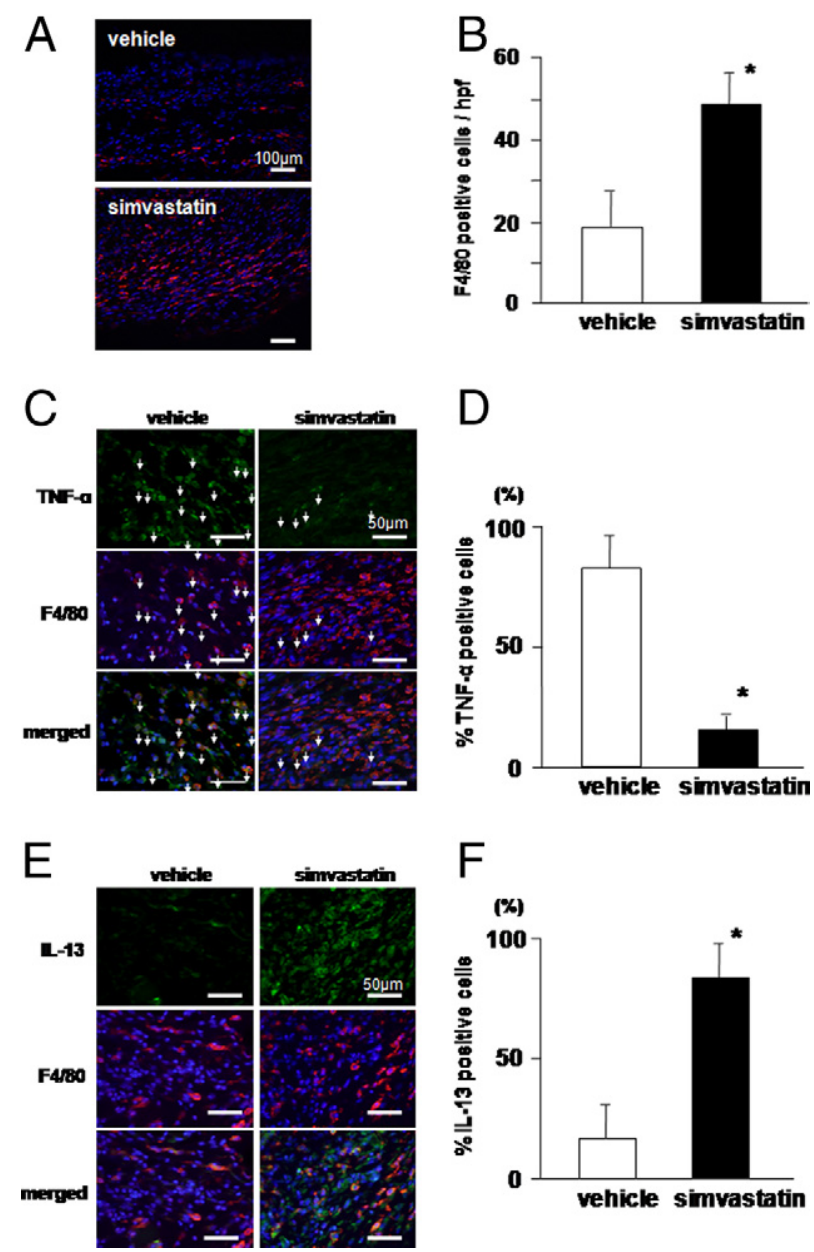

Figure 6. Effects of simvastatin on macrophage infiltration and phenotype in granulation tissue. A: Representative photomicrographs of the immunostained wound edge at 7 days after wound creation. Red fluorescence corresponds to F4/80-positive macrophages. Scale bar $=100 \mu \mathrm{m}$. B: The macrophage count, quantified as described in Materials and Methods. ${ }^{*} P<0.05$ versus vehicle $(n=5)$. C: Representative photomicrographs of the immunodetection of TNF- $\alpha$ and F4/80 in histologic sections from vehicle- or simvastatin-treated wounds (original magnification $\times 400$ ). Scale bar $=50$ $\mu \mathrm{m}$. Green and red fluorescence corresponds to TNF- $\alpha$-positive cells and F4/80-positive macrophages, respectively. Yellow indicates TNF- $\alpha$-producing M1 phenotype macrophages (white arrows). D: Quantification of percentage of TNF- $\alpha$-positive macrophages, as described in Materials and Methods. ${ }^{*} P<0.001$ versus vehicle ( $n=5$ in each group). E: Representative photomicrographs of immunodetection of IL-13 and F4/80 in histologic sections from vehicle- or simvastatin-treated wounds (original magnification $\times 400$ ). Scale bar $=50 \mu \mathrm{m}$. Green and red fluorescence correspond to IL-13-positive cells and F4/80-positive macrophages, respectively. Yellow indicates IL-13-producing M2 phenotype macrophages. F: Quantification of percentage of IL-13-positive macrophages, as described in Materials and Methods. ${ }^{*} P<0.001$ versus vehicle $(n=5$ in each group). 
A

VEGF-C

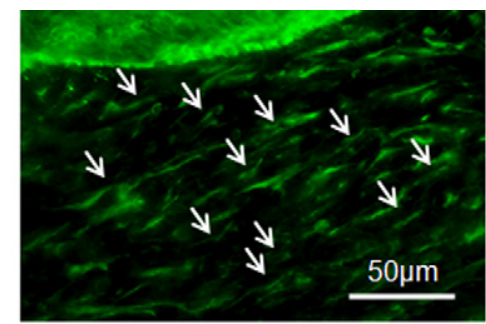

F $4 / 80$

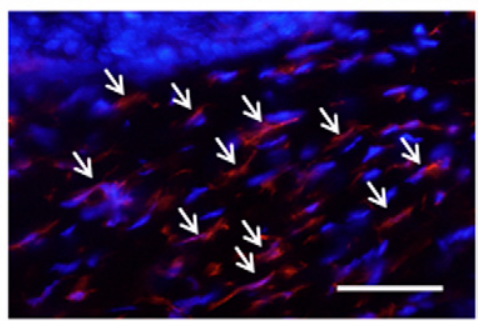

merged

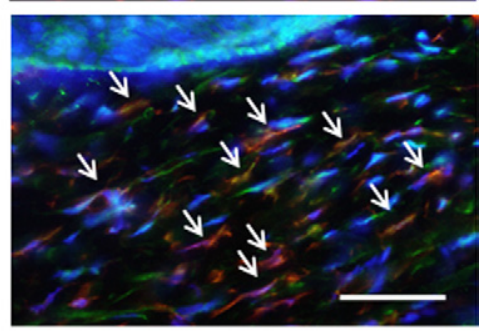

B

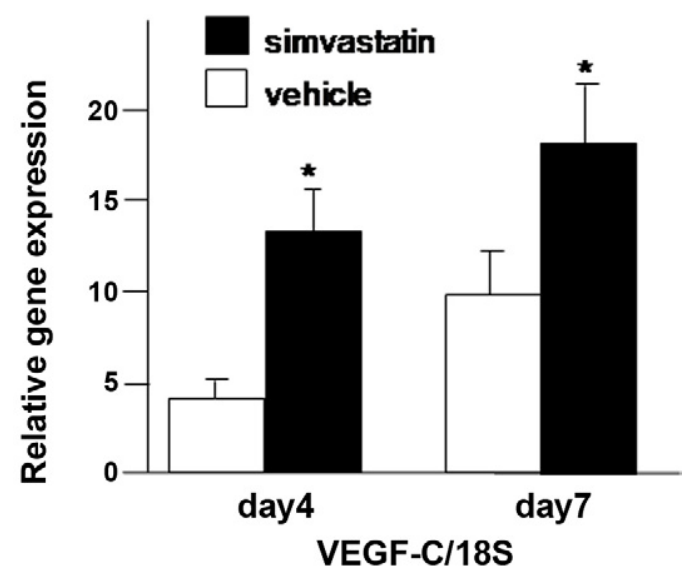

Figure 7. VEGF-C expression in granulation tissue. A: Representative photomicrographs of the immunostained wound edge treated with simvastatin at 7 days after wound creation. Green and red fluorescence indicates VEGF-C expression and F4/80-positive macrophages, respectively. Original magnification, $\times 400$. Arrows indicate double-positive cells. Scale bar $=50 \mu \mathrm{m}$. B: Quantitative RT-PCR of VEGF-C in wound granulation tissue. Gene expression levels were normalized based on the level of an internal reference gene, $18 \mathrm{~S}$. ${ }^{*} P<0.05$ versus vehicle $(n=5)$.

new therapeutic strategy for treatment of local ischemic conditions, such as those in patients with diabetic ulcers.

Lymphangiogenesis is a major factor in diabetic refractory wound healing. ${ }^{4,5}$ Therefore, we focused on the effects of simvastatin on wound lymphangiogenesis. Recent studies have suggested that several biological functions of LECs are partially regulated by the AKT/PI3K/mTOR pathway. ${ }^{25,26}$ Consistent with these observations, capillary morphogenesis of LECs was significantly stimulated by simvastatin as an effect on vascular endothelial cells that was, at least in part, regulated by the AKT/PI3K/mTOR pathway.
Our results suggest that the mechanisms underlying the lymphangiogenic effects of simvastatin in LECs might be similar to those for angiogenic effects. These mechanisms include antiapoptosis and promotion of capillary morphogenesis because LECs develop from a vascular network in an embryonic stage, ${ }^{27}$ and these cells have a similar lineage. However, contrary to our expectation, simvastatin did not promote proliferation of LECs in vitro. During the wound healing process, new lymphatics are formed in newly generated granulation tissue, indicating that proliferation of preexisting lymphatic vessels is needed.

Because simvastatin did not promote the proliferation of LECs, we evaluated other possible sources of Iymphangiogenic factors. Several reports suggest that infiltrating macrophages contribute to lymphangiogenesis as the major producer of VEGF-C in cutaneous wound healing, ${ }^{4,5}$ and therefore we evaluated the effects of simvastatin on macrophages. Macrophages carry VEGF receptor 3, in addition to producing VEGF-C, and thus act as both autocrine and paracrine factors. We have previously reported that healing impairment in diabetes involves reduced lymphangiogenesis and suppressed macrophage function, such as recruitment to inflammatory sites and secretion of growth factors. ${ }^{5}$ In this study, the number of infiltrating macrophages in granulation tissue was significantly increased by topical application of simvastatin, and most of these macrophages produced VEGF-C. These observations suggest that simvastatin recovers lymphangiogenic function that is impaired in macrophages under diabetic conditions.

Increased apoptosis is a major concern in wound healing in a diabetic state. ${ }^{3,28-31}$ Hyperglycemia induces proinflammatory cytokines, such as TNF- $\alpha$, and oxidative stress, which result in increased apoptosis in diabetes. Our study found that most infiltrating macrophages in diabetic wounds had an M1 proinflammatory phenotype producing abundant TNF- $\alpha$. Simvastatin decreased $\mathrm{H}_{2} \mathrm{O}_{2}$-induced apoptosis in LECs in vitro and increased M2 anti-inflammatory phenotype macrophages in granulation tissue in vivo. We suggest that this anti-apoptotic effect of simvastatin also plays an important role, in addition to promotion of angiogenesis and lymphangiogenesis.

Increased infiltration of macrophages induced by simvastatin may have further benefits because the histologic scores of diabetic wounds were significantly improved by topical application of simvastatin. The histologic score reflects the degree of maturation of granulation tissue, including inflammation, collagen deposition, and reepithelialization, in addition to neovascularization. Macrophages play a central role in all stages of wound healing and orchestrate the wound healing process ${ }^{32}$ by exerting proinflammatory functions and facilitating wound healing during the early stage and stimulating proliferation of fibroblasts, keratinocytes, and endothelial cells in the proliferative stage. Because the main focus of this study was lymphangiogenesis, we did not investigate the effects of simvastatin on reepithelialization or formation of extracellular matrix. This will require further experiments in a future study.

In conclusion, regulation of apoptosis and capillary differentiation are essential for development of functional lymphatics during wound healing. The findings of the present study suggest that topical simvastatin can stimulate lymp- 
hangiogenesis directly and indirectly via stimulation of macrophages. Vascular remodeling induced by simvastatin might have therapeutic potential in patients with microvascular dysfunction, such as that in diabetic foot ulcer, a major cause of morbidity in the growing population of patients with diabetes. A future investigation is warranted to determine the potential clinical utility of this approach.

\section{References}

1. Jeffcoate WJ, Harding KG: Diabetic foot ulcers. Lancet 2003, 361: 1545-1551

2. Lerman OZ, Galiano RD, Armour M, Levine JP, Gurtner GC: Cellular dysfunction in the diabetic fibroblast: impairment in migration, vascular endothelial growth factor production, and response to hypoxia. Am J Pathol 2003, 162:303-312

3. Fadini GP, Albiero M, Menegazzo L, Boscaro E, Pagnin E, Iori E, Cosma C, Lapolla A, Pengo V, Stendardo M, Agostini C, Pelicci PG, Giorgio M, Avogaro A: The redox enzyme p66Shc contributes to diabetes and ischemia-induced delay in cutaneous wound healing. Diabetes 2010, 59:2306-2314

4. Saaristo A, Tammela T, Farkkila A, Karkkainen M, Suominen E, YlaHerttuala S, Alitalo K: Vascular endothelial growth factor-C accelerates diabetic wound healing. Am J Pathol 2006, 169:1080-1087

5. Maruyama K, Asai J, li M, Thorne T, Losordo DW, D'Amore PA: Decreased macrophage number and activation lead to reduced lymphatic vessel formation and contribute to impaired diabetic wound healing. Am J Pathol 2007, 170:1178-1191

6. Oliver G, Detmar M: The rediscovery of the lymphatic system: old and new insights into the development and biological function of the lymphatic vasculature. Genes Dev 2002, 16:773-783

7. Witte MH, Bernas MJ, Martin CP, Witte CL: Lymphangiogenesis and lymphangiodysplasia: from molecular to clinical lymphology. Microsc Res Tech 2001, 55:122-145

8. Ji RC: Characteristics of lymphatic endothelial cells in physiological and pathological conditions. Histol Histopathol 2005, 20:155-175

9. Werner N, Nickenig G, Laufs U: Pleiotropic effects of HMG-CoA reductase inhibitors. Basic Res Cardiol 2002, 97:105-116

10. Landmesser U, Engberding N, Bahlmann FH, Schaefer A, Wiencke A, Heineke A, Spiekermann S, Hilfiker-Kleiner D, Templin C, Kotlarz D, Mueller M, Fuchs M, Hornig B, Haller H, Drexler H: Statin-induced improvement of endothelial progenitor cell mobilization, myocardial neovascularization, left ventricular function, and survival after experimental myocardial infarction requires endothelial nitric oxide synthase. Circulation 2004, 110:1933-1939

11. Kureishi Y, Luo Z, Shiojima I, Bialik A, Fulton D, Lefer DJ, Sessa WC, Walsh K: The HMG-CoA reductase inhibitor simvastatin activates the protein kinase Akt and promotes angiogenesis in normocholesterolemic animals. Nat Med 2000, 6:1004-1010

12. Bitto A, Minutoli L, Altavilla D, Polito F, Fiumara T, Marini H, Galeano M, Calo M, Lo Cascio P, Bonaiuto M, Migliorato A, Caputi AP, Squadrito F: Simvastatin enhances VEGF production and ameliorates impaired wound healing in experimental diabetes. Pharmacol Res 2008, 57:159-169

13. Emanueli C, Monopoli A, Kraenkel N, Meloni M, Gadau S, Campesi I, Ongini E, Madeddu P: Nitropravastatin stimulates reparative neovascularisation and improves recovery from limb ischaemia in type- 1 diabetic mice. Br J Pharmacol 2007, 150:873-882

14. Otuki MF, Pietrovski EF, Cabrini DA: Topical simvastatin: preclinical evidence for a treatment of skin inflammatory conditions. J Dermatol Sci 2006, 44:45-47
15. Greenhalgh DG, Sprugel KH, Murray MJ, Ross R: PDGF and FGF stimulate wound healing in the genetically diabetic mouse. Am J Pathol 1990, 136:1235-1246

16. Asai J, Takenaka H, Katoh N, Kishimoto S: Dibutyryl cAMP influences endothelial progenitor cell recruitment during wound neovascularization. J Invest Dermatol 2006, 126:1159-1167

17. Asai J, Takenaka H, Kusano KF, li M, Luedemann C, Curry C, Eaton E, Iwakura A, Tsutsumi Y, Hamada H, Kishimoto S, Thorne T, Kishore R, Losordo DW: Topical sonic hedgehog gene therapy accelerates wound healing in diabetes by enhancing endothelial progenitor cell-mediated microvascular remodeling. Circulation 2006, 113:2413-2424

18. Abràmoff $M D$, Magalhães $P J$, Ram $S$ : J: image processing with ImageJ. Biophotonics Int 2004, 11:36-42

19. Jacobi J, Jang JJ, Sundram U, Dayoub H, Fajardo LF, Cooke JP: Nicotine accelerates angiogenesis and wound healing in genetically diabetic mice. Am J Pathol 2002, 161:97-104

20. Hirakawa S, Hong YK, Harvey N, Schacht V, Matsuda K, Libermann $\mathrm{T}$, Detmar M: Identification of vascular lineage-specific genes by transcriptional profiling of isolated blood vascular and lymphatic endothelial cells. Am J Pathol 2003, 162:575-586

21. Maruyama K, li M, Cursiefen C, Jackson DG, Keino H, Tomita M, Van Rooijen N, Takenaka H, D'Amore PA, Stein-Streilein J, Losordo DW, Streilein JW: Inflammation-induced lymphangiogenesis in the cornea arises from CD11b-positive macrophages. J Clin Invest 2005, 115:2363-2372

22. Nakao T, Shiota M, Tatemoto $Y$, Izumi $Y$, Iwao H: Pravastatin induces rat aortic endothelial cell proliferation and migration via activation of PI3K/Akt/ mTOR/p70 S6 kinase signaling. J Pharmacol Sci 2007, 105:334-341

23. Cantoni S, Cavallini C, Bianchi F, Bonavita F, Vaccari V, Olivi E, Frascari I, Tassinari R, Valente S, Lionetti V, Ventura C: Rosuvastatin elicits KDRdependent vasculogenic response of human placental stem cells through PI3K/AKT pathway. Pharmacol Res 2012, 65:275-284

24. Zhao TT, Trinh D, Addison CL, Dimitroulakos J: Lovastatin inhibits VEGFR and AKT activation: synergistic cytotoxicity in combination with VEGFR inhibitors. PLoS One 2010, 5:e12563

25. Luo Y, Liu L, Rogers D, Su W, Odaka Y, Zhou H, Chen W, Shen T, Alexander JS, Huang S: Rapamycin inhibits lymphatic endothelial cell tube formation by downregulating vascular endothelial growth factor receptor 3 protein expression. Neoplasia 2012, 14:228-237

26. Dellinger MT, Brekken RA: Phosphorylation of Akt and ERK $1 / 2$ is required for VEGF-A/VEGFR2-induced proliferation and migration of Iymphatic endothelium. PLoS One 2011, 6:e28947

27. Oliver G: Lymphatic vasculature development. Nat Rev Immunol 2004, 4:35-45

28. Hamed S, Ullmann Y, Egozi D, Daod E, Hellou E, Ashkar M, Gilhar A, Teot L: Fibronectin potentiates topical erythropoietin-induced wound repair in diabetic mice. J Invest Dermatol 2011, 131:1365-1374

29. Badr G: Supplementation with undenatured whey protein during diabetes mellitus improves the healing and closure of diabetic wounds through the rescue of functional long-lived wound macrophages. Cell Physiol Biochem 2012, 29:571-582

30. Ahmad J, Zubair M, Malik A, Siddiqui MA, Wangnoo SK: Cathepsin-D, Adiponectin, TNF-alpha, IL-6 and hsCRP plasma levels in subjects with diabetic foot and possible correlation with clinical variables: a multicentric study. Foot (Edinb) 2012, 22:194-199

31. Dave GS, Kalia K: Hyperglycemia induced oxidative stress in type-1 and type-2 diabetic patients with and without nephropathy. Cell Mol Biol (Noisy-le-grand) 2007, 53:68-78

32. Mahdavian Delavary B, van der Veer WM, van Egmond M, Niessen FB, Beelen RH: Macrophages in skin injury and repair. Immunobiology 2011, 216:753-762 